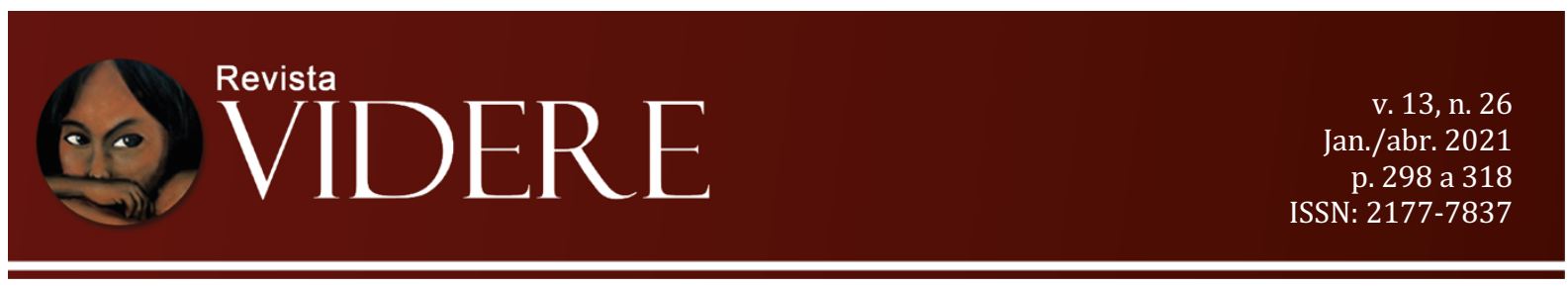

\title{
EXTRATIVISMOS E COLONIALIDADE: A RESERVA NACIONAL DO COBRE - BRASIL
}

\author{
EXTRATIVISM AND COLONIALITY: THE RESERVA NACIONAL DO COBRE- \\ BRAZIL
}

\section{EXTRACTIVISMOS Y COLONIALIDAD: LA RESERVA NACIONAL DEL COBRE - BRASIL}

Katya Regina Isaguirre-Torres

Doutora em meio ambiente e desenvolvimento Universidade Federal do Paraná

E-mail:Katya.isaguirre@ufpr.br

OrcidID: https://orcid.org/0000-0001-7237-2629

\begin{abstract}
Resumo: O artigo analisa qual a noção de sustentabilidade se faz presente nos discursos estatais de desenvolvimento, tendo como referência o caso da Reserva Nacional do Cobre (RENCA). A revisão bibliográfica e a análise de legislação foram complementadas pela consulta de reportagens e notícias dos anos de 2017 e 2018. Os objetivos buscam analisar as justificativas para a extinção da RENCA e identificar a percepção da sociedade. Seus resultados revelam que o discurso estatal do desenvolvimento se encontra funcionalizado ao crescimento econômico e, portanto, é insuficiente para lidar com as dimensões socioculturais e a questão da natureza. $\mathrm{O}$ caso necessita ser avaliado em conjunto com os demais projetos de flexibilização ambiental e os retrocessos nos direitos sociais, em conexão com o ciclo da dependência extrativista. A mobilização social contra a extinção da reserva desperta a atenção para a necessidade e a força do debate público na discussão das alternativas ao desenvolvimento.
\end{abstract}

PALAVRAS-CHAVE: Extrativismo. sustentabilidade. desenvolvimento. Reserva Nacional do Cobre. participação social.

Abstract: The article analyzes which notion of sustainability is present in state development discourses, with reference to the case of the "Reserva Nacional do Cobre". The literature review and legislation analysis were supplemented by consulting on-line reports and news from the years 2017 and 2018. The objectives are to analyze the justifications for the extinction of the RENCA and identify society's perception. The results showed that the state development discourse is functionalized to economic growth and, therefore, is insufficient to deal with the socio-cultural dimensions and the issue of nature. The case needs to be evaluated in conjunction with the other environmental flexibilization projects and the setbacks of social rights, in connection with the cycle of extractive dependency. The social mobilization against the 
extinction of the reserve draws attention to the need and the strength of public debate in the evaluation of alternatives to development.

Keywords: Extractivism. sustainability. development. Reserva Nacional do Cobre. social participation.

Resumen: El artículo analiza qué noción de sustentabilidad está presente en los discursos de desarrollo del Estado, con referencia al caso de la Reserva Nacional del Cobre (RENCA). La revisión bibliográfica y el análisis de la legislación se complementaron con la consulta de informes y reportajes de los años 2017 y 2018. Los objetivos son analizar las justificaciones de la extinción de RENCA e identificar la percepción de la sociedade. Los resultados revelan que el discurso estatal del desarrollo se funcionaliza al crecimiento económico y, por tanto, es insuficiente para abordar las dimensiones socioculturales y la cuestión de la naturaleza. El caso debe ser evaluado en conjunto con los otros proyectos de flexibilización ambiental y los retrocesos en los derechos sociales, en relación con el ciclo de dependencia extractiva. La movilización social contra la extinción de la reserva llama la atención sobre la necesidad y fuerza del debate público en la evaluación de alternativas al desarrollo.

Palabras clave: Extractivismo. sustentabilidad. desarrollo. Reserva Nacional do Cobre. participación social.

\section{Introdução}

O artigo 225 da Constituição da República consagra o "meio ambiente" como um direito humano e fundamental de todos(as). Esse importante direito difuso de terceira dimensão está relacionado ao critério da sustentabilidade, que toma força na discussão da agenda política mundial a partir de 1987 e se torna fundamental para repensar as estratégias de desenvolvimento. A sustentabilidade reúne diferentes dimensões que devem ser aplicadas em conjunto, envolvendo assim perspectivas de equidade presentes e intergeracionais do ponto de vista social, cultural, ambiental e econômico. O critério da sustentabilidade também requer a compreensão das características do desenvolvimento, identificando as contradições e a transformação progressiva dos bens comuns em recursos naturais e como isso reflete na distribuição dos espaços de qualidade ambiental.

Nesse viés, o artigo adota a expressão "socioambiental" como qualificadora do critério da sustentabilidade. A referência ao socioambientalismo decorre, em primeiro lugar, da interpretação integrada do conjunto dos direitos humanos e fundamentais expressos na Constituição, os quais apresentam diferentes desafios para assegurar o acesso efetivo aos bens essenciais para a reprodução da vida. Em segundo lugar, utiliza-se também a expressão socioambiental tendo em vista a pluralidade das relações sociais e destas com a natureza, o que revela a "interface entre biodiversidade e sociobiodiversidade, permeada pelo multiculturalismo, pela plurietnicidade e pelo enfoque humanista" (SANTILLI, 2005, p. 93). 
A expressão "desenvolvimento sustentável” aparece com mais força nos diálogos ambientais internacionais a partir de 1987, com a aprovação pela Assembleia da Organização das Nações Unidas (ONU) do Relatório Brundtland (também conhecido como o documento Our Common Future). O relatório consagrou a sustentabilidade como princípio do desenvolvimento, pela necessidade de levar em conta que a satisfação das necessidades presentes não pode comprometer a continuidade da capacidade das gerações futuras na sustentação da vida. O documento trouxe as bases teóricas do que se conhece como desenvolvimento sustentável, as quais eram discutidas desde a Conferência das Nações Unidas sobre o Desenvolvimento e Meio Ambiente Humano, que ocorreu na cidade de Estocolmo no ano de 1972. A Conferência de Estocolmo é considerada como um marco da entrada da questão ambiental na agenda política mundial.

O consenso para aprovação do Relatório Bundtland decorreu de uma série de eventos sociopolíticos, tais como as transformações do Estado Social, as crises do petróleo do início da década de 80 e também de desastres socioambientais como Chernobyl (1986). Como afirma Naína Pierri “a fórmula de desenvolvimento sustentável desloca definitivamente o velho questionamento ecologista ao crescimento e o coloca como condição central da sustentabilidade ecológica, e a esta se admite como condição para o crescimento" (PIERRI, 2002, p. 21). Posteriormente, a Conferência das Nações Unidas sobre o Meio ambiente e Desenvolvimento (ECO-92), realizada na cidade do Rio de Janeiro, no ano de 1992, procurou definir algumas estratégias e metas para a sustentabilidade. A conferência gerou a Declaração do Rio sobre Meio Ambiente, a Agenda XXI, a Convenção marco sobre mudanças climáticas, a Convenção sobre Diversidade Biológica e a Declaração de Princípios sobre o Manejo, Conservação e Desenvolvimento Sustentável de todos os tipos de Florestas.

No entanto, não existe uma só noção de sustentabilidade, sendo possível sua interpretação a partir de diferentes correntes do pensamento socioambiental. A trajetória da incorporação da sustentabilidade ao conceito de desenvolvimento é também permeada por discussões teóricas que tratam dos sentidos diferenciados de natureza e também as interpretações decorrentes dos contextos de crise do sistema capitalista moderno colonial. Enrique Leff, ao analisar a trajetória do discurso da sustentabilidade, salienta que a sua noção dominante, construída sob a influência da globalização econômica, apresenta uma existência simultânea de dois significados. O primeiro, "que implica a internalização das condições ecológicas que suportam o processo econômico. Outro, que aduz a durabilidade do próprio processo econômico" (LEFF, 1998, p. 19). Para o autor, a noção dominante apresenta a sustentabilidade ecológica como uma condição de sustentabilidade do processo econômico. 
A sustentabilidade, quando funcionalizada ao processo econômico, busca soluções pela aplicação dos mecanismos de mercado ou com a internalização dos custos ambientais nos processos produtivos; porém, deixa de apreciar a desigualdade na apropriação e distribuição dos bens naturais em escala local e mundial, avançando na apropriação da natureza e das culturas pela racionalidade da economia política moderna. Como salienta Souza Filho, considerando a perspectiva de Locke, que identifica as bases do capitalismo na propriedade privada, no individualismo e na determinação de valor conforme o trabalho humano incorporado, a economia política moderna "significa uma separação radical entre bens 'humanizados', transformados pelo homem e, portanto, sujeito à propriedade privada, dos bens da natureza, sem valor, fora do mercado" (SOUZA FILHO, 2015, p.92).

A separação moderna humanidade/natureza é um elemento importante no repensar das estratégias de desenvolvimento e, em consequência, nas disputas pela noção de sustentabilidade. A reconexão entre humanos, não humanos e natureza pode conduzir a outros sentidos de sustentabilidade os quais, na linha do pensamento socioambientalista, conduziriam a reflexões acerca das contradições do projeto moderno. Segundo Castro Gómez, a modernidade possui estruturalmente uma dupla governabilidade jurídica. De um lado, as políticas de subjetivação dos estados nacionais e, de outro, "a governamentabilidade exercida para fora pelas potências hegemônicas do sistema-mundo moderno/colonial, em sua tentativa de assegurar o fluxo de matérias-primas da periferia em direção ao centro. Ambos os processos formam parte de uma única dinâmica estrutural" (CASTRO-GÓMEZ, 2005, p. 91).

Um último elemento teórico é relevante nessa reflexão, que é o conceito de extrativismo. Como salienta Alberto Acosta e Ulrich Brand:

$\mathrm{O}$ extrativismo se refere a atividades que removem, na maioria das vezes de forma intensiva, grandes volumes de recursos naturais, e a cultivos agroindustriais que se utilizam de muitos insumos, com o objetivo de exportar segundo a demanda dos países centrais, sem processamento - ou com processamento limitado - dos produtos (ACOSTA \& BRAND, 2018, p.36).

Um aspecto importante da acumulação primário exportadora é sua decorrência da desigual divisão internacional do trabalho (ACOSTA \& BRAND, 2018, p. 38-39), a qual distribui aos países do sul papéis sociais na economia mundial que os mantêm presos a um ciclo de dependência e, portanto, de permanência na periferia do sistema mundo. De acordo com a análise dos autores existem diferentes extrativismos, os quais requerem grandes investimentos e geram graves impactos sociais, ambientais e culturais.

Entender a permanência do extrativismo no modelo de desenvolvimento dominante é condição para discutir as alternatividades possíveis, as quais apresentam diferentes visões da 
natureza e também de formas de organização comunitárias. As experiências existentes, produzidas por populações vulneráveis aos projetos de desenvolvimento, sejam essas produzidas à margem ou parcialmente inseridas no sistema capitalista, podem incentivar a análise da problemática das condições estruturantes que determinam a geração e a manutenção das desigualdades sociais e ainda, como essas questões se encontram ligadas com uma determinada visão de natureza. Recuperar a conexão com a natureza é um passo importante para atingir um ideal de sustentabilidade socioambiental.

A partir dessas referências teóricas o artigo tem como objetivo geral analisar qual a noção de sustentabilidade se encontra presente nos discursos estatais de desenvolvimento, tendo como referência o caso da Reserva Nacional do Cobre no Brasil (RENCA). O estudo de caso foi escolhido por tratar da mineração e ser representativo do extrativismo enquanto característica do modelo de exploração latino-americano. Outro fator para a seleção do caso foi a sua grande repercussão social, o que mobilizou entidades, indivíduos e grupos, atuantes ou simpatizantes da causa ambiental. As referências da análise do discurso (ORLANDI, 2009) permitiram problematizar a relação de forças e os diferentes sentidos produzidos a partir da ação do estado e da reação da sociedade.

\section{A trajetória normativa da Reserva Nacional do Cobre}

A criação da RENCA surgiu em razão de disputas empresariais para mineração na região. No início da década de 80, a Companhia Estatal Vale do Rio Doce (privatizada em 1996 e hoje com o nome de Vale S.A) possuía interesses voltados na área de exploração entre os rios Paru e Jari por meio de sua subsidiária Docegeo, mesma área de interesse da empresa petrolífera britânica BP. De acordo com o geólogo Breno Augusto dos Santos, gerente da Docegeo à época, a criação da reserva "foi uma decisão política para contornar um impasse entre a BP e a Vale" (FELLET, 2017). Vale recordar que a questão da estrangeirização da Amazônia já contava com os exemplos de Fordlândia (1927) e do Projeto Jari, desenvolvido a partir de 1967 e que envolvia a confluência dos rios Jari e Amazonas, entre os Estados do Pará e Amapá.

O debate acerca do modelo de desenvolvimento para a Amazônia ocupou destaque nas redes sociais e na mídia com a publicação do Decreto $n^{\circ}$ 9142, de 22 de agosto de 2017, que extinguiu a Reserva Nacional do Cobre (RENCA). A Reserva Nacional do Cobre (RENCA) foi criada pelo Decreto $n^{\circ}$ 89.404/1984, do então presidente João Figueiredo. A RENCA tinha a finalidade de estabelecer uma espécie de "estoque minerário" para o Cobre, cabendo à 
Companhia de Pesquisa de Recursos Minerais (CPRM) as pesquisas destinadas à determinação e avaliação das ocorrências de cobre e seus associados.

O Decreto $n^{\circ}$ 9142/2017 foi elaborado em atenção ao que dispôs a Portaria $n^{\circ} 128$, de 30 de março de 2017, do Ministério de Minas e Energia. A Portaria nº128/2017 apresentou a extinção da RENCA tendo em vista "a importância de se criar mecanismos para viabilizar a atração de novos investimentos para o setor mineral" e justificou que essa medida "viabilizaria o acesso ao potencial mineral existente na Região e estimularia o desenvolvimento econômico dos Estados envolvidos" (MINISTÉRIO DE MINAS E ENERGIA, PORTARIA 128, 2017). Ainda de acordo com a Portaria n ${ }^{\circ}$ 128/2017, o decreto seria necessário para “desonerar as áreas objetos de requerimentos apresentados e pendentes de decisão ou títulos eventualmente outorgados sem amparo na legislação pertinente" (MINISTÉRIO DE MINAS E ENERGIA, PORTARIA 128, 2017). A Portaria mantinha em vigência os títulos minerários já outorgados e deixaria para análise aqueles pendentes de decisão e que tivessem sido protocolizados antes da entrada em vigor do Decreto $n^{\circ} 89.404$, de 24 de fevereiro de 1984. Os requerimentos de títulos minerários que teriam por objeto áreas da RENCA, pendentes de decisão e protocolizados no período de vigência do Decreto $n^{\circ} 89.404 / 84$, seriam indeferidos pela autoridade competente. Os indeferimentos, no entanto, ficariam sobrestados até a vigência do Decreto de extinção da RENCA. Essas áreas seriam colocadas em disponibilidade para fins de pesquisa pelo Departamento Nacional de Produção Mineral (DNPM) (MINISTÉRIO DE MINAS E ENERGIA, PORTARIA 128, 2017, art. $4^{\circ}$ ).

O governo federal, após a repercussão negativa da publicação do Decreto $\mathrm{n}^{\mathrm{o}}$ 9142/2017, lançou uma nota à imprensa (MINISTÉRIO DAS RELAÇÕES EXTERIORES, 2017), na qual afirmava que a extinção não tratava de uma reserva ambiental e que seus efeitos não atingiriam unidades de conservação existentes na área. A nota informava ainda que eventuais empreendimentos futuros que viessem a atingir unidades de conservação estaduais teriam que cumprir as exigências ambientais de licenciamento. Destaque-se da nota o seguinte trecho:

A Renca não é um paraíso, como querem fazer parecer, erroneamente, alguns. Hoje, infelizmente, territórios da Renca original estão submetidos à degradação provocada pelo garimpo clandestino de ouro, que, além de espoliar as riquezas nacionais, destrói a natureza e polui os cursos d água com mercúrio (MINISTÉRIO DAS RELAÇÕES EXTERIORES, 2017).

A nota ressaltava que a nova legislação (em referência indireta ao decreto $\mathrm{n}^{\mathrm{o}}$ 9142/2017) permitiria coibir a exploração ilegal do garimpo, recolocando sob o controle do Estado a administração de jazidas minerais importantes. A nota fechava com uma menção ao 
desenvolvimento sustentável e ressaltava o compromisso do governo na conjugação da preservação ambiental, com geração de renda e emprego para as populações locais.

Em reportagem publicada no dia 26 de agosto de 2017, Ricardo Senra noticiou que, em um evento realizado no mês de março de 2017, na cidade de Toronto no Canadá, "o ministro de Minas e Energia, Fernando Coelho Filho, anunciou a empresários do país que a área de preservação amazônica seria extinta, e que sua exploração seria leiloada entre empresas privadas" (SENRA, 2017). Nesse seminário foi apresentado pelo governo o fim da RENCA, junto a um pacote de medidas de reformulação do setor mineral brasileiro, que incluía a criação de Agência Nacional de Mineração e outras iniciativas para estimular o setor (SENRA, 2017).

Em nota de esclarecimento, do dia 28 de agosto de 2017, o Ministério de Minas e Energia confirmou a divulgação realizada no evento em Toronto, dizendo que a questão já era discutida por técnicos do Ministério desde o segundo semestre de 2016, com amplo debate (MINISTÉRIO DE MINAS E ENERGIA, 2017). O amplo debate, de acordo com a reportagem, foi contestado pelo Comitê Nacional em Defesa dos Territórios Frente à Mineração, que reúne 110 ONGs, sindicatos e movimentos sociais, o qual afirmou não ter ocorrido qualquer comunicado prévio aos pesquisadores da área e comunidades sobre a extinção da RENCA (SENRA, 2017).

Após a publicação do Decreto $n^{\circ}$ 9142/2017 teve início uma série de manifestações da sociedade civil em favor e contra a extinção da RENCA. Os argumentos favoráveis à extinção da RENCA concentravam-se na necessidade de crescimento econômico e argumentavam que a sustentabilidade se daria pelos controles ambientais já existentes para as empresas de mineração. O movimento "Todos pela Amazônia”, contrário à extinção da reserva, alertou para a preservação das florestas amazônicas e realizou um ato público na Câmara dos Deputados. Nesse ato ocorreu a entrega aos presidentes da Câmara e do Senado de um documento assinado por 1,5 milhão de pessoas (G1, 2017). Como argumentos contrários apresentavam-se os impactos às dimensões sociais, ambientais e culturais da sustentabilidade, recordando os projetos de lei atualmente existentes que se voltam à flexibilização do licenciamento ambiental. Outro argumento apresentado mencionava as falhas no monitoramento e controle socioambiental das atividades minerárias, tal como aconteceu no rompimento da barragem de Fundão, da mineradora Samarco (Mariana/Minas Gerais). Como disse Adriana Ramos, entrevistada por Amélia Gonzalez à época dos fatos, a extinção da RENCA envolve várias questões inter-relacionadas ao controle e fiscalização da questão ambiental. Dentre elas, destaca-se: 
A lei do licenciamento tende a fragilizar todo o sistema de gestão ambiental no geral, vai olhar também para uma série de outras questões que não tem outra forma de controle. O grande problema da mineração é ter uma atividade que tem uma regulação numa lógica de interesse público e que se coloca isso na perspectiva do interesse privado de outros países. Todo um interesse nacional subordinado a um interesse de mercado. Se a lógica de exploração da Amazônia for pautada exclusivamente sob o potencial econômico de empresas estrangeiras, qualquer perspectiva de preservar a floresta e pessoas fica para trás (GONZALEZ, 2017).

A repercussão nacional e internacional das denúncias de ambientalistas, povos originários e organizações não governamentais fizeram com que o Decreto $\mathrm{n}^{\mathrm{o}} 9142$ fosse primeiro suspenso e depois revogado, o que ocorreu via Decreto ${ }^{\circ}$ 9147, também publicado no ano de 2017. O Decreto ${ }^{\circ}$ 9147/2017 manteve a extinção da RENCA e proibiu a autorização de pesquisa mineral, a concessão de lavra, a permissão de lavra garimpeira, licenciamento e qualquer outro tipo de direito de exploração minerária onde houvesse sobreposição com unidades de conservação ou com terras indígenas (BRASIL, DECRETO 9147, 2017, art. $3^{\circ}$ ). A regulamentação do decreto, no entanto, foi recebida também por críticas uma vez que não detalhava medidas de efetivo controle ambiental.

No judiciário foram propostas ações com o objetivo de questionar a inconstitucionalidade e suspender os efeitos do Decreto. Em ação popular distribuída para a $21^{\mathrm{a}}$ Vara Federal do Distrito Federal, os efeitos dos decretos foram suspensos liminarmente ${ }^{1}$. A inconstitucionalidade da extinção via decreto foi levantada pelo Ministério Público Federal no Amapá, por meio de ação civil pública, que igualmente requereu a suspensão liminar do decreto, a qual foi deferida em setembro de 2017. Os argumentos apresentados salientam que a região da RENCA, embora de finalidade mineral, se encontra em sobreposição com diferentes áreas protegidas e sua extinção ameaçaria a diversidade biológica e cultural. A ação proposta pelo MPF sustentou a proteção constitucional de espaços territorialmente protegidos e a invasão de competência, tendo em vista, que a reserva só poderia sofrer alteração e supressão através de lei, de acordo com o mandamento constitucional previsto no art. 225 , $\S 1^{\circ}$, inciso III, da Constituição Federal de 1988 (MINISTÉRIO PÚBLICO FEDERAL, 2017).

A discussão pareceu encerrar-se com o Decreto n ${ }^{\circ}$ 9159, de 25 de setembro de 2017, por meio do qual o governo federal revogou o Decreto $\mathrm{n}^{\circ} 9147$, revigorando o Decreto $\mathrm{n}^{\mathrm{o}}$ $89.404 / 1984$ e o Decreto $n^{\circ}$ 92.107/85. Porém, no dia 12 de junho de 2018, foi publicado o

\footnotetext{
${ }^{1}$ Nota explicativa: A sentença final julgou extinta a ação em razão da revogação dos decretos e a superveniente perda do objeto. A sentença foi confirmada pelo Tribunal Regional Federal da $1^{a}$ Região (AC 101078880.2017.4.01.3400, DESEMBARGADOR FEDERAL DANIELE MARANHAO COSTA, TRF1 - QUINTA TURMA, PJe 17/01/2020).
} 
Decreto $n^{\circ}$ 9406, que regulamenta o Decreto-Lei n ${ }^{\circ}$ 227/1967 (Código de Mineração), a Lei no 6.567/78, a Lei $\mathrm{n}^{\mathrm{o}} 7.805 / 89$, e parte da Lei $\mathrm{n}^{\circ}$ 13.575/2017. O decreto estabelece em seu artigo 72:

Art. 72. Em zona declarada reserva nacional de determinada substância mineral ou em áreas específicas objeto de pesquisa ou lavra sob o regime de monopólio, o Poder Executivo federal poderá, mediante condições especiais condizentes com os interesses da União e da economia nacional, outorgar autorização de pesquisa ou concessão de lavra de outra substância mineral, quando os trabalhos relativos à autorização ou à concessão forem compatíveis e independentes dos relativos à substância da reserva nacional ou do monopólio.

$\S 1^{\circ}$ Nas reservas nacionais, a pesquisa ou lavra de outra substância mineral somente será autorizada ou concedida nas condições especiais estabelecidas em ato do Ministro de Estado de Minas e Energia, ouvidos, previamente, os órgãos governamentais interessados.

$\S 2^{\circ}$ Nas áreas sob regime de monopólio, a pesquisa ou a lavra de outra substância mineral somente será autorizada ou concedida nas condições especiais estabelecidas em ato do Ministro de Estado de Minas e Energia, ouvido, previamente, o órgão executor do monopólio.

$\S 3^{\circ}$ Verificada, a qualquer tempo, a incompatibilidade ou a dependência dos trabalhos, a autorização de pesquisa ou concessão de lavra será revogada.

$\S 4^{\circ} \mathrm{O}$ direito de prioridade não se aplica às hipóteses previstas neste artigo e cabe ao Poder Executivo federal outorgar a autorização ou a concessão tendo em vista os interesses da União e da economia nacional. (BRASIL, BRASIL, DECRETO 9406, 2018, art. 72).

A anulação do artigo 72 foi requerida em ação civil pública pela Ministério Público Federal no Amapá. De acordo com reportagem publicada no site G1, em 16 de junho de 2018, o MPF comentou que o novo decreto seria uma "forma disfarçada de reintroduzir a proposta de forma indevida, sem consulta aos envolvidos" (G1 AP, 2018). Seus fundamentos, em síntese, sustentam a inconstitucionalidade da alteração via decreto e também a necessidade de serem seguidas as regras da consulta livre, prévia e informada aos povos indígenas e populações tradicionais, interessados e diretamente atingidos pela medida, nos termos da Convenção 169 da Organização Internacional do Trabalho (OIT) (MINISTÉRIO PÚBLICO FEDERAL, 2018).

\section{A proteção ambiental das áreas protegidas}

A mineração é uma atividade com alto potencial para geração de impactos ambientais negativos e, por essa razão, a Constituição Federal de 1988 estabeleceu no parágrafo $2^{\circ}$, do art. 225, que todas as atividades de mineração têm o dever, conexo à atividade que realizam, de recuperação do meio ambiente degradado. Esse dever impõe o devido controle e monitoramento, de acordo com os princípios da prevenção e também a cautela antecipada para 
a possibilidade de danos futuros, para os quais não é necessário a previsão prévia, dentro daquilo que se reconhece pelo princípio da precaução.

A possibilidade de extinção da RENCA conduz à reflexão do seu regime de proteção. De fato, a reserva nacional não está prevista na tipologia das unidades de conservação da Lei $n^{\circ}$ 9.985/2000. Sua criação guarda semelhança com a noção de reserva de exploração do sistema colonial, a exemplo do "Regimento do Pau-Brasil" editado em 1605 e Carta Régia de 13 de março de 1797. Segundo Medeiros "a finalidade desse tipo de proteção florestal "advinha dos diversos inventários realizados a serviço da coroa portuguesa visando determinar a existência de recursos naturais estratégicos que poderiam ser explorados e controlados" (MEDEIROS, 2005. p. 43).

No caso específico da RENCA, há que se considerar que entre o período de sua constituição até os dias atuais, houve a sobreposição de áreas com designação de unidades de conservação federais e estaduais, além de terras indígenas demarcadas. Esse conjunto de áreas protegidas forma um mosaico de unidades de conservação, o qual é responsável por assegurar a qualidade ambiental da região. A Convenção sobre Diversidade Biológica (CDB), em seu artigo $2^{\circ}$, define área protegida como aquela "que é destinada, ou regulamentada, e administrada para alcançar objetivos específicos de conservação”. A definição é complementada pelas diretrizes estabelecidas no art. $8^{\circ}$ da CDB, que trata da conservação “in situ”. Em sua alínea “j”, o artigo $8^{\circ}$ reconhece o dever de "respeitar, preservar e manter o conhecimento, inovações e práticas das comunidades locais e populações indígenas com estilo de vida tradicionais relevantes à conservação e à utilização sustentável da diversidade biológica" (BRASIL, DECRETO LEGISLATIVO 2, 1994).

No ano de 2008, a Comissão Mundial de Áreas Protegidas da União Internacional de Conservação da Natureza (UICN) atualizou o conceito como: "um espaço geográfíco claramente definido, reconhecido, dedicado e gestionado por meios legais e outros tipos de meios eficazes, para conseguir a conservação a longo prazo da natureza e de seus serviços ecossistêmicos e seus valores culturais associados (Dudley, 2008)". (LAUSCHE, 2012, p.14).

As áreas protegidas, de acordo com a UICN e a CDB, são amplas e se voltam tanto para a proteção da biodiversidade como também para o cuidado com os diferentes saberes e modos de vida relacionados ao território. Não há uma tipologia única de áreas protegidas, as quais podem abranger espaços públicos ou privados, sendo que sua finalidade relaciona-se ao critério do "in dubio pro natura", que rege a gestão socioambiental do território. Como exemplos, citam-se as unidades de conservação, as áreas de preservação permanente e de reserva legal, as terras indígenas e de povos tradicionais, as reservas da biosfera etc. 
Um outro conceito importante a ser relacionado ao caso é o de espaço territorial especialmente protegido, apresentado na Constituição Federal de 1988. Esse conceito guarda relação com as definições de áreas protegidas e é igualmente abrangente. $\mathrm{Na}$ análise desse conceito e sua aplicação, Paulo Affonso Leme Machado bem salienta que a proteção constitucional, "não está limitada a nomes ou regimes jurídicos de cada espaço territorial, pois qualquer espaço entra na órbita do art. 225, $\S 1^{\circ}$, III, desde que se reconheça que ele deva ser especialmente protegido" (MACHADO, 2014, p. 168).

Nesses espaços, de alta relevância para a proteção da natureza e das culturas, a Constituição Federal de 1988 proíbe qualquer utilização que possa comprometer a integridade dos atributos que justifiquem sua proteção. A alteração e a supressão de um espaço territorial especialmente protegido só pode acontecer por meio de lei, para que se tenha o tempo adequado de debate popular. A necessidade de alteração ou supressão apenas por lei é uma decorrência direta do direito humano e fundamental previsto no art. 225 da $\mathrm{CF} / 88$, o qual reconhece como titulares toda a sociedade. Sua característica difusa reforça ainda mais a necessidade de informação e participação qualificada nos debates que se voltem à garantir efetividade desse direito, reforçando sua característica de essencialidade para a reprodução da vida. Nesse aspecto, Paulo Affonso Leme Machado salienta que a participação democrática é fundamental para a gestão de áreas protegidas (e também, para espaços territorialmente protegidos, uma vez que são conceitos em conexão), a fim de evitar que elas sejam "mutiladas e deturpadas ao sabor do imediatismo e de soluções demagógicas, às vezes intituladas como de interesse social ou de interesse público" (MACHADO, 2014, p. 168). No caso em análise, a extinção da RENCA por decreto, em se tratando de área e espaço territorialmente protegido, contraria o que dispõe a Constituição Federal de 1988.

No tocante à força do Sistema Nacional de Unidades de Conservação para fazer frente à pressão das mineradoras é preciso avaliar a inter-relação que existe entre a Lei no 9985/2000, a Constituição Federal de 1988 e a Convenção 169 da OIT. Quanto às unidades de conservação de proteção integral, a proibição de atividades minerárias decorre de interpretação do $\operatorname{art} .7^{\circ}$ da Lei $n^{\circ}$ 9985/2000, que admite apenas o uso indireto dos recursos naturais. O uso indireto, definido pelo art. $2^{\circ}$, inciso IX, da Lei $n^{\circ}$ 9985/2000, é aquele "que não envolve consumo, coleta, dano ou destruição dos recursos naturais” (BRASIL, LEI 9985, 2000, art. 2º, IX). Ainda que $\mathrm{o}$ artigo $7^{\circ}$ não faça referência expressa à proibição, não existe compatibilidade lógica entre a liberação de atividades de mineração e o objetivo de preservação das UC's de proteção integral, uma vez que a extração de recursos minerais produz degradação ambiental de longa duração. 
No caso das Unidades de Conservação de Uso Sustentável há que se realizar uma análise prévia. O objetivo das UC's de uso sustentável é realizar a conservação da natureza com o uso sustentável de parcela (e não da totalidade) dos seus recursos naturais. Para a unidade de conservação de uso sustentável denominada Reserva Extrativista existe proibição expressa para atividades de mineração, conforme $\S 6^{\circ}$ do artigo 18 da Lei 9985/2000. Para as demais UC's de uso sustentável há que se verificar se a atividade de mineração não conflita com os objetivos de criação da unidade e ainda, o seu plano de manejo.

O Ministério Público Federal, na publicação "Regularização Fundiária em Unidades de Conservação", analisa a possibilidade de mineração em cada uma das UC's de uso sustentável. De acordo com o MPF, em breve síntese, a mineração é possível nas Áreas de Proteção Ambiental (APAs), desde que prevista no plano de manejo e que exista compatibilidade entre o seu objetivo e não ocorram conflitos em seu zoneamento. Análise semelhante existe para Área de Relevante Interesse Ecológico (ARIE) reforçando-se o dever de compatibilidade em razão da UC apresentar características naturais extraordinárias ou abrigar exemplares raros da biota, como consta de sua definição. No caso da Floresta Nacional (FLONA) a atividade de mineração não é permitida. De acordo com o MPF a proibição decorre da incompatibilidade de proteger os recursos florestais e também pelo fato da FLONA admitir a permanência de populações tradicionais. Na Reserva de Fauna (REFAU) a mineração somente será permitida desde que compatível com os objetivos de sua criação e sem que ocorram conflitos no zoneamento previsto no plano de manejo. Na Reserva de Desenvolvimento Sustentável (RDS) o MPF entende que não é permitida a mineração, seja pelos objetivos da UC, seja por assegurar os direitos socioambientais da comunidade tradicional que ali vive. Por fim, para a Reserva Particular do Patrimônio Natural (RPPN) não é permitida a mineração, tendo em vista que o item que previa a possibilidade de mineração foi vetado quando da apreciação da Lei 9985/2000 por apresentar incompatibilidade com os objetivos de criação da UC. (BRASIL, MPF, 2014, p. 31-35).

É preciso lembrar também que, pelo princípio da informação, os processos de análise para atividades minerárias devem garantir o debate público, seja quando da elaboração do plano de manejo ou nos processos de licenciamento ambiental. Essa participação, cujo fundamento decorre da Constituição Federal de 1988, determina ainda que, na existência de povos originários e/ou comunidades tradicionais, cujos territórios tenham sido direta ou indiretamente atingidos, há que se observar o processo de consulta livre, prévia e informada previsto na Convenção 169 da OIT. 
Para as terras indígenas a pesquisa e a lavra das riquezas minerais só podem ser efetivadas com autorização do Congresso Nacional, respeitado o processo de consulta livre, prévia e informada estabelecido pela Convenção 169 da OIT. Nas terras ocupadas por povos e comunidades tradicionais é igualmente importante a observância das regras da convenção, ressaltando-se o direito à autodeterminação e a necessidade de garantia efetiva de participação e de consulta prévia, pois o direito ao território liga-se à condição de ser e de existir dos povos originários e tradicionais.

No ano de 2017 a Coordenação de Criação de Unidades de Conservação (COCUC), a Coordenação Geral de Criação, Planejamento e Avaliação de Unidades de Conservação (CGCAP), a Diretoria de Criação e Manejo de Unidades de Conservação (DIMAN), ligadas ao Instituto Chico Mendes de Conservação da Biodiversidade (ICMBIO) elaboraram uma nota técnica conjunta ${ }^{2}$ para analisar a proposta de revogação dos Decretos no 89.404, de 24 de fevereiro de 1984 e o Decreto no 92.107, de 10 de dezembro de 1985, que altera o Decreto no 89.404, de 1984. Nessa nota destacam que:

A área definida pela RENCA compreende um polígono de $46.450 \mathrm{~km} 2$ que
apresenta sobreposição com parte de três unidades de conservação federais, o
Parque Nacional Montanhas de Tumucumaque, a Estação Ecológica do Jari e
a Reserva Extrativista do Rio Cajari, bem como de parte de quatro unidades
de conservação estaduais; a Reserva Biológica Estadual Maicuru e a Floresta
Estadual Paru. no Pará; a Reserva de Desenvolvimento Sustentável Estadual
Rio Iratapuru e Floresta Estadual do Amapá, no Amapá; e ainda parte de duas
terras indígenas, a TI Paru D'Este e a TI Waiãpi. (COCUC et al, 2017, p.2).

A nota afirma existir elevada demanda minerária na região, com 8.892 títulos minerários no interior da reserva, segundo dados obtidos junto ao Departamento Nacional de Produção Mineral - DNPM (COCUC et al, 2017, p.2) Em suas conclusões observaram que não é permitida mineração nas unidades de conservação de proteção integral (parque, estação ecológica e reserva biológica), bem como na reserva extrativista. Nas unidades de conservação de uso sustentável a nota alerta para a necessidade de observação dos seus decretos de criação e dos respectivos planos de manejo (COCUC et al, 2017, p. 3). Por fim a nota ressalva que nos processos de licenciamento devem ser observados os "títulos referentes às coleções hídricas que adentrem as unidades de conservação", tendo em vista os danos ambientais e recomenda ao DNPM os cancelamentos dos títulos minerários em sobreposição com as unidades de conservação em que não são permitidas a atividade de mineração. A nota encerra

\footnotetext{
${ }^{2}$ Nota explicativa: a nota técnica não foi encontrada nos órgãos oficiais. Ela foi divulgada em reportagem de Maurício Tuffani, no site Direto da Ciência (TUFFANI, 2017).
} 
recomendando a consulta aos órgãos ambientais dos estados do Pará e Amapá (COCUC et al, 2017, p. 3).

Um outro elemento importante nessa discussão é que as unidades de conservação devem possuir zonas de amortecimento nos seus entornos, bem como corredores ecológicos, ambos instrumentos de gestão ambiental do território. As zonas de amortecimento devem estar previstas nos planos de manejo a fim de assegurar a diminuição dos impactos ambientais das atividades próximas à unidade de conservação. Os corredores ecológicos são, por sua vez, importantes para assegurar o fluxo de fauna e para mitigação dos efeitos da fragmentação dos ecossistemas. Todo esse sistema, que se forma com o mosaico de áreas protegidas da região, pode ser duramente afetado pela autorização de projetos de mineração em larga escala.

O direito humano e fundamental ao ambiente equilibrado, ao lado do direito ao patrimônio cultural e imaterial, ambos previstos na Constituição Federal de 1988, reforçam a força da interpretação da Lei do SNUC em favor da natureza e de suas gentes. Porém, a dependência da previsão nos planos de manejo trazem fragilidade, uma vez que é conhecido que, em épocas de crises de mercado, o discurso dominante do crescimento econômico a qualquer preço ganha força. Sob esse aspecto, vale recordar que o plano de manejo de uma unidade de conservação, tanto em seu planejamento como em casos de revisão, deve resultar de um procedimento que assegure "a participação efetiva das populações locais na criação, implantação e gestão das unidades de conservação", em conformidade com o artigo $5^{\circ}$, inciso III, do SNUC.

\section{O discurso do desenvolvimento no debate da Reserva Nacional do Cobre}

Interessante, nesse ponto, questionar qual seria a noção de desenvolvimento sustentável que se pode ler a partir da portaria e da nota à imprensa do Ministério de Minas e Energia. Segundo Orlandi (2009) a análise de discurso é uma mediação entre seres humanos e a realidade natural e social, que compreende a linguagem como movimento. "Essa mediação, que é o discurso, torna possível tanto a permanência e a continuidade quanto o deslocamento e a transformação do homem e a realidade em que ele vive" (ORLANDI, 2009, p.15). Nesse viés, procurou-se analisar a portaria e a nota à imprensa como uma mensagem, interligada ao contexto da realidade e identificando-se um emissor (Estado) e um receptor (Sociedade).

A discussão que se coloca a partir da RENCA é que ela revela a manutenção de uma matriz extrativista de raízes coloniais. $\mathrm{O}$ argumento que a abertura de processos de exploração minerária por empresas teria por objetivo coibir o garimpo ilegal não é coerente, pois os 
impactos ambientais, sociais e culturais só aumentarão em escala e velocidade. A mineração "quase sempre acarreta, no final de seu ciclo de extração, um quadro de significativa degradação ambiental. Tanto é que a extração de minerais é classificada pela Lei no ${ }^{\circ}$ 6.938/1981, em seu anexo VIII, como atividade potencialmente poluidora de grau alto" (BRASIL, MPF, 2014, p. 28).

O discurso governamental afirmou que a exploração minerária traria desenvolvimento econômico aos Estados, na geração de emprego e renda, respeitando-se a sustentabilidade. No entanto, não explicou como lidaria com os impactos sociais, culturais e ambientais de uma região de importância mundial como a Amazônia. Assim, a mensagem do emissor mantém a noção dominante da sustentabilidade como funcionalizada ao crescimento econômico.

A perspectiva de crescimento econômico não dimensiona com exatidão os diferentes tipos de danos que podem decorrer da mineração. Horácio Machado Araóz descreve o que define como "violências do modelo minerador", apresentando uma série de consequências sociais, ambientais e econômicas que degradam a vida coletiva, tais como o derramamento de substâncias tóxicas que contaminam rios e solos; a destruição de patrimônios arqueológicos, ambientais e culturais; o deslocamento forçado de comunidades; o sufocamento de economias locais (agrícolas, pesqueiras, pecuaristas, turísticas etc.); a corrupção de empresas, empresários e agentes públicos; as violações de direitos e normas, dentre outros (ARAÓZ, 2020 [2013], p. 16-17).

O autor considera a mineração como uma forma extrema de extrativismo, por sua "condição fundamental constituinte do sistema mundo capitalista-colonial-patriarcal" (2020 [2013], p. 33). A dialética da dependência, utilizada pelo autor a partir das referências Karl Polanyi, Ruy Mauro Marini e Milton Santos, apresenta uma "forma de crescimento superficial, momentâneo e esporádico", ligado a um "empobrecimento estrutural de longa duração", resultante de um processo econômico, cultural e político que acarreta a "deterioração secular, sistêmica, da capacidade produtiva das populações e dos territórios afetados" (ARAÓZ, 2020 [2013], p. 29). A dependência, decorrente da desigual divisão internacional do trabalho na economia mundial, fragiliza a situação dos países minério-dependentes e assim, na queda dos preços internacionais da matéria-prima exportada, a resposta desses países é trazer mais extrativismo, expandindo a ação para áreas até então inexploradas do território e, com isso, aumentando os impactos sociais, culturais e ambientais. A sustentabilidade, no modelo da minério-dependência, não se faz presente.

A sustentabilidade socioambiental requer um rearranjo produtivo e também a mudança de perspectiva das relações humanas com a natureza, sem descuidar de reconhecer a 
historicidade, a importância dos saberes e dos modos de vida dos povos originários e tradicionais, importantes guardiões da biodiversidade. Nesse ideal de sustentabilidade, e também na discussão das alternativas ao desenvolvimento, é importante avaliar a dependência, que se lê também a partir dos efeitos práticos do colonialismo e da colonialidade do poder e do saber.

A análise de Aníbal Quijano sobre a colonialidade do poder é um argumento importante para perceber a dependência histórica. $\mathrm{O}$ espaço do artigo não permite analisar em profundidade o pensamento do autor, mas é possível trazer alguns elementos para tratar do modelo extrativista dependente em sua historicidade. A complexidade e a profundidade da colonialidade do poder se articula a partir do conceito abstrato de raça e as formas de controle e exploração do trabalho na América Latina, que "naturalizaram" a dominação entre europeus e não europeus, a partir da legitimação de práticas e discursos de superioridade/inferioridade. Como bem observou Quijano, todas as formas de controle e exploração do trabalho, assim como “a exploração-apropriação e distribuição dos produtos" voltados ao mercado mundial, estabeleceu pela primeira vez um padrão global de controle do trabalho que constituiu uma geografia do capitalismo, definiu hierarquias e determinou papéis sociais no sistema mundo moderno (QUIJANO, 2011 [2000], p. 120).

A colonialidade do poder e do saber sustentaram a concepção da modernidade, “associada às ideias de novidade, do avançado, do racional-científico, laico, secular", que são associadas a esse conceito e assim deixando de reconhecer "que esse fenômeno é possível em todas as culturas e em todas as épocas históricas". (QUIJANO, 2011 [2000], p. 122). Como ensinou Quijano, essa mesma relação poder-saber da colonialidade estabeleceu uma dependência histórico-cultural, uma vez que os senhores brancos latino-americanos, donos do poder político, não tinham interesses comuns com a maioria da população. Adotando a perspectiva eurocêntrica, a construção da noção de Estado-nação se deu em contrariedade com os interesses dos povos e assim "a colonialidade do poder ainda exerce seu domínio, na maior parte da América Latina, contra a democracia, a cidadania, a nação e o Estado-nação moderno" (QUIJANO, 2011 [2000], p. 135). Daqui decorre a importância da descolonização do pensamento, sem deixar de reconhecer os efeitos da colonialidade, para repensar a permanência do padrão extrativista do sistema capital moderno colonial quando da discussão do desenvolvimento e de suas alternativas.

O caso da RENCA, como representativa de modelo de desenvolvimento dominante extrativista, necessita ser avaliado em conjunto com as propostas de desenvolvimento para a região, a fim de repensar se o uso de técnicas mais avançadas de mineração, o avanço dos 
projetos minerários, o desmatamento florestal da grande agricultura e da pecuária intensiva, a manutenção da matriz energética com o uso de combustíveis fósseis e o modelo hidrelétrico são, de fato, condizentes com a sustentabilidade para o país e, especialmente, para a região amazônica. $\mathrm{O}$ momento atual exige a amplitude do debate acerca dos efeitos da manutenção do modelo extrativista dependente e, nesse aspecto, a mobilização da sociedade civil foi significativa para demonstrar que a participação social se faz importante na discussão das alternativas ao desenvolvimento. Ainda que o debate à época dos fatos não tenha tratado do conjunto das iniciativas de flexibilização das normas ambientais e/ou dos retrocessos nos direitos sociais, ela representou um outro sentido de sustentabilidade, que nos permite entender que há movimento na análise discursiva; que são possíveis outras leituras, outros mundos. Para isso, é fundamental a manutenção do Estado Democrático e a defesa das liberdades, para que os processos participativos possam ser feitos de forma adequada e acessível a todos os grupos sociais, especialmente os diretamente afetados pelos diferentes extrativismos. É esse o contexto que ambienta o debate da RENCA, ou seja, há que se avaliar o conjunto das políticas de desenvolvimento em sua complexidade, considerando a quem interessa a prática extrativista e quais grupos suportam os seus impactos sociais, ambientais e culturais.

\section{Conclusão}

A problemática desse artigo buscou enfrentar teoricamente a trajetória do princípio da sustentabilidade e os desafios de sua aplicação na prática, tendo como referência o caso da extinção da Reserva Nacional do Cobre (RENCA), articulando a mensagem do Estado e a reação da sociedade. O caso é emblemático por que demonstrou a importância do debate público e da participação social em temas socioambientais. A sustentabilidade ecológica funcionalizada ao crescimento econômico e adotada no discurso governamental para a justificativa de extinção da RENCA, é condizente com a permanência de um perfil extrativista dependente de desenvolvimento, de raízes coloniais.

O princípio da sustentabilidade é interpretado por diferentes correntes ideológicas, sendo dominante a noção que advém do pensamento liberal. Em contrapartida, outros sentidos de sustentabilidade surgem a partir da realidade vivida por diferentes sujeitos sociais e, dentre eles, destacou-se a sustentabilidade socioambiental, que busca reconectar a relação humana com a natureza, admitindo a abstração da ruptura moderna e também a necessidade de compreensão dos efeitos práticos do colonialismo e da colonialidade do poder-saber na concepção do desenvolvimento e sua dependência do extrativismo. 
A decisão de extinção da reserva não pode ser entendida de forma pontual e isolada, mas sim, conectada ao conjunto de reformas legislativas que impõem riscos de retrocessos sociais e ambientais. Tais reformas não são pensadas para atingir patamares de sustentabilidade, mas sim, se conectam com os diferentes extrativismos, os quais em cada crise do sistemamundo avançam para regiões até então inexploradas e ampliam os conflitos socioambientais. O ciclo de crescimento superficial e de empobrecimento estrutural, na esteira do pensamento de Horácio Machado Araóz, invisibiliza outras alternativas ao desenvolvimento e mantém a aplicação reduzida do princípio da sustentabilidade, submetido à lógica da incorporação dos custos ambientais nos processos produtivos. A dificuldade de se ver os antagonismos sobre as dinâmicas do modelo de desenvolvimento extrativista dependente, como a extinção da RENCA instiga a compreender, envolve não apenas os impedimentos de caráter econômico e político, mas também, os obstáculos epistemológicos e culturais.

A RENCA é uma área e um espaço territorial especialmente protegido e, caso o decreto fosse mantido, seria necessário reconhecer sua inconstitucionalidade pela aplicação do artigo 225 da CF/88. A sua qualidade ambiental demanda um planejamento equilibrado, capaz de equacionar proteção da natureza com a territorialidade e as culturas dos povos que habitam esse espaço. A reação da sociedade civil diante da mensagem do Estado indicou a dinamicidade do discurso, as relações de força e de sentidos que foram produzidos tanto na emissão, quanto na recepção da mensagem. Por fim, entende-se que a participação social é fundamental para outras interpretações possíveis do conceito de desenvolvimento e do princípio da sustentabilidade.

\section{Referências}

ACOSTA, Alberto; BRAND, Ulrich. Pós-extrativismo e decrescimento: saídas do labirinto capitalista. São Paulo: Elefante, 2018.

Ambientalistas, indígenas e artistas se unem em ato a favor da Amazônia. G1 Jornal Nacional. 12 set. 2017. Disponível em: http://g1.globo.com/jornalnacional/noticia/2017/09/ambientalistas-indigenas-e-artistas-se-unem-em-ato-favor-daamazonia.html. Acesso em 13 mar. 2021.

ARAÓZ, Horácio Machado. Mineração, genealogia do desastre: o extrativismo na América como origem da modernidade. São Paulo: Elefante. 2020. Primeira edição publicada em 2013.

BRASIL. Decreto legislativo $\mathrm{n}^{\circ}$ 2, de 1994. Disponível em:

http://www2.camara.leg.br/legin/fed/decleg/1994/decretolegislativo-2-3-fevereiro-1994358280-publicacaooriginal-1-pl.html. Acesso em 13 mar. 2021. 
BRASIL. Decreto ${ }^{\circ}$ 9.147, de 28 de agosto de 2017. Disponível em: http://www.planalto.gov.br/ccivil 03/ ato2015-2018/2017/decreto/d9147.htm. Acesso em 10 mar. 2021.

BRASIL. Decreto n ${ }^{\circ}$ 9.406, de 12 de junho de 2018. Disponível em: http://www.planalto.gov.br/ccivil_03/_Ato2015-2018/2018/Decreto/D9406.htm. Acesso em 10 mar. 2021.

BRASIL. MINISTÉRIO PÚBLICO FEDERAL: câmara de coordenação e revisão, 4. Regularização fundiária em unidades de conservação. Brasília: MPF, 2014. Disponível em: http://www.mpf.mp.br/atuacao-tematica/ccr4/dados-da-atuacao/publicacoes/roteiros-da-4accr/manual-regularizacao-fundiaria-em-unidade-conservacao.pdf. Acesso em 13 mar. 2021.

CASTRO-GÓMEZ, Santiago. Ciências sociais, violência epistêmica e o problema da “invenção do outro". In: LANDER, Edgardo (Org). A colonialidade do saber, eurocentrismo e ciências sociais: perspectivas latino-americanas. Buenos Aires: Clacso, 2005, p. 169-186. Disponível em:

http://biblioteca.clacso.edu.ar/ar/libros/lander/pt/lander.html.

COORDENAÇÃO DE CRIAÇÃO DE UNIDADES DE CONSERVAÇÃO et al. Nota técnica conjunta COCUC/DIMAN/ICMBIO/DAP/SBio/MMA, nº 11 de 2017. Disponível em: http://diretodaciencia.com/wp-content/Anexos/Nota-Tecnica_ICMBio_Renca.pdf. Acesso em 13 mar. 2021.

FELLET, João. Como preocupação com interesse estrangeiro levou militares a criar reserva extinta por Temer. BBC News Brasil. 25. Agosto de 2017. Disponível em: https://www.bbc.com/portuguese/brasil-41044596. Acesso em 10 mar. 2021.

GONZALEZ, Amélia. Revogar a Renca nem é o problema em si. G1 portal de notícias. 25 ago. 2017. Disponível em: http://g1.globo.com/natureza/blog/nova-etica-social/post/revogarrenca-nem-e-o-problema-em-si-diz-ambientalista.html. Acesso em 10 mar. 2021.

LAUSCHE, Barbara. (2012). Directrices para la legislación relativa a áreas protegidas. UICN, Gland, Suiza. Bonn: UICN, 2012. Disponível em: https://portals.iucn.org/library/sites/library/files/documents/EPLP-081-Es.pdf. Acesso em 13 dez. 2020.

LEFF, Enrique. Saber ambiental: sustentabilidad, racionalidade, complejidad, poder. Madrid/México: Siglo XXI editores; PNUMA; UNAM, 1998.

MACHADO, Paulo Affonso Leme. Direito ambiental brasileiro. São Paulo: Malheiros, 2014.

MEDEIROS, Rodrigo. Evolução das tipologias e categorias de áreas protegidas no Brasil. Ambient. soc., Campinas, v. 9, n. 1, p. 41-64, June 2006. Disponível em: $<$ http://www.scielo.br/scielo.php?script=sci_arttext\&pid=S1414753X2006000100003\&lng=en\&nrm=iso >. Acesso em: 13 mar. 2021. http://dx.doi.org/10.1590/S1414-753X2006000100003. 
MINISTÉRIO DAS RELAÇÕES EXTERIORES. Nota à imprensa sobre o decreto que extinguiu a Reserva Nacional de Cobre e Associados (Renca). [s.d.] Disponível em: https://sistemas.mre.gov.br/kitweb/datafiles/Munique/pt-br/file/Nota\%20a\%20Imprensa.pdf. Acesso em 10 mar. 2021.

MINISTÉRIO DE MINAS E ENERGIA. Portaria nº 128, de 30 de março de 2017. Disponível em: https://www.gov.br/anm/pt-br/centrais-deconteudo/copy of legislacao/portarias-do-ministerio-de-minas-e-energia/portarias-doministro/portaria-no-128-de-30-de-marco-de-2017-dou-de-07042017-2013-trata-da-reservanacional-de-cobre-e-associados-2013-renca/view. Acesso em 10 mar. 2020.

MINISTÉRIO PÚBLICO FEDERAL - Amapá. MPF/AP quer suspensão dos efeitos do decreto de extinção da Renca. 28 ago. 2017. Disponível em: http://www.mpf.mp.br/ap/salade-imprensa/noticias-ap/mpf-ap-quer-suspensao-dos-efeitos-do-decreto-de-extincao-da-renca. Acesso em: 13 mar. 2021.

MINISTÉRIO PÚBLICO FEDERAL - Amapá. MPF quer anulação de parte do Decreto que permite exploração mineral em reservas nacionais. 14 de jun. 2018. Ministério Público Federal. Disponível em: http://www.mpf.mp.br/ap/sala-de-imprensa/noticias-ap/mpf-queranulacao-de-parte-do-decreto-que-permite-exploracao-mineral-em-reservas-nacionais. Acesso em 10 mar. 2021.

MPF fala em 'disfarce' e avalia que decreto federal pode abrir exploração na Renca. G1 Amapá - Rede Amazônica. 16 de jun 2018. Disponível em: https://g1.globo.com/ap/amapa/noticia/mpf-fala-em-disfarce-e-avalia-que-decreto-federalpode-abrir-exploracao-na-renca.ghtml. Acesso em: 13 mar. 2021.

ORLANDI, Eni Puccinelli. Análise de discurso: princípios e procedimentos. Campinas/SP: Pontes, 2009.

PIERRI, Naína. Análisis crítico del instrumento de evaluación de impacto ambiental: su aplicación en Uruguay. Tesis de Doctorado. Curitiba: Universidade Federal do Paraná, 2002.

QUIJANO, Aníbal. Colonialidade do poder, Eurocentrismo e América Latina. In: LANDER, Edgardo (Org). La Colonialidad del saber: eurocentrismo y ciências sociales. 2 ed. Buenos Aires/Argentina, CLACSO, 2005 [2000]. Disponível em: http://biblioteca.clacso.edu.ar/clacso/sur-sur/20100624103322/12_Quijano.pdf. Acesso em 13 mar. 2021.

SANTILLI, Juliana. Socioambientalismo e novos direitos: proteção jurídica à diversidade biológica e cultural. São Paulo: Peirópolis, 2005.

SENRA, Ricardo. Mineradoras canadenses souberam de extinção de reserva na Amazônia 5 meses antes do anúncio oficial. BBC Brasil em Washington, 26 ago. 2017. Disponível em: http://www.bbc.com/portuguese/brasil-41033211. Acesso em 10 mar. 2021.

SOUZA FILHO, Carlos Frederico Marés de. De como a natureza foi expulsa da modernidade. In: Revista Crítica de Direito. N. 5. Vol. 66. São Paulo: 2015, p. 88-104. 
TUFFANI, Maurício. Da forma como foi feita, extinção da Renca traz risco para a Amazônia. Direto da ciência: análise, opinião e jornalismo investigativo. 25 ago. 2017. Disponível em: http://www.diretodaciencia.com/2017/08/25/da-forma-como-foi-feita-extincao-da-renca-trazrisco-para-a-amazonia/. Acesso em 13 mar. 2021.

Data de recebimento: 18.11 .2020

Data de aprovação: 19.01.2021 